\title{
INFLUÊNCIA DE SUBSTRATOS NA GERMINAÇÃO DE SEMENTES DE Anadenanthera colubrina (VELL.) BRENAN EM CONDIÇÕES DE CASA DE VEGETAÇÃO ${ }^{1}$
}

\author{
Kívia Soares de Oliveira ${ }^{2}$, Kaline Soares de Oliveira ${ }^{3}$ e Magdi Ahmed Ibrahim Aloufa ${ }^{4}$
}

\begin{abstract}
RESUMO - Anadenanthera colubrina (Vell.)Brenan), uma Leguminosae da sub-família Mimosoideae, popularmente conhecida como angico, é uma espécie nativa do bioma caatinga, bastante conhecida pelo teor de tanino encontrado em sua casca, por sua utilização na construção civil, na indústria de curtume e na recuperação de áreas degradadas. Considerando a importância da espécie, este trabalho teve como objetivo avaliar a eficiência de diferentes substratos na germinação de sementes de angico. Os estudos foram conduzidos na casa de vegetação do Laboratório de Biotecnologia de Conservação de Espécies Nativas da Universidade Federal do Rio Grande do Norte. Para tanto, realizou-se experimento com quatro tratamentos incluindo quatro repetições com 100 sementes por tratamento e temperatura média de $26^{\circ} \mathrm{C}$. Foram realizadas contagens diárias durante 30 dias. Os tratamentos utilizados foram: $\mathrm{T}_{0}$-vermiculita, $\mathrm{T}_{1}$-húmus, $\mathrm{T}_{2}$-areia e $\mathrm{T}_{3}$-areia barrada. Foram analisadas as seguintes variáveis: porcentagem de emergência, índice de velocidade de emergência de plântulas e tempo médio de germinação. O delineamento experimental foi inteiramente casualizado e as médias comparadas pelo teste de Tukey a $5 \%$ de significância. Observou-se que, quanto à porcentagem de emergência, a vermiculita, o húmus e areia apresentaram diferença significativa, com melhor desempenho em relação à areia barrada; quanto ao índice de velocidade de emergência e ao tempo médio de germinação, estatisticamente, não houve diferença significativa entre os substratos. Portanto, diante dos resultados pôde-se observar que A. colubrina apresenta um bom potencial germinativo em qualquer um dos substratos avaliados, exceto em areia barrada. Contudo, para a germinação e emergência de plântulas de angico recomenda-se a utilização dos substratos vermiculita, areia ou húmus.
\end{abstract}

Palavras-chave: Caatinga, Mimosoideae e Germinação.

\section{INFLUENCE OF THE SUBSTRATE ON SEED OF GERMINATION OF ANGICO (Anadenanthera colubrina (VELL.) BRENAN) UNDER GREENHOUS}

\begin{abstract}
Anadenanthera colubrina (Vell.) Brenan, a Leguminosae, belonging to the subfamily Mimosoideae, popularly known as angico, is a native species to Caatinga biome, known by its content of tannin in the bark, its utilization in construction, tanning industry and the recovery of degraded areas. Due to the importance of the species, the objective of this study was to evaluate the efficiency of different substrates on the seeds germination. The study was carried out in the greenhouse of the Laboratory of Biotechnology of Native Species Conservation at the Rio Grande do Norte Federal University. It was set up an experiment with four treatments including four replicates with 100 seeds per treatment and at the average temperature of $26^{\circ} \mathrm{C}$. Observations were made daily for 30 days. The treatments used were: $T_{0-}$ vermiculite, $T_{1}$-humus, $T_{2}$-sand and $T_{3}$-clay. The following variables were analyzed: percentage of seedling emergence, seedling emergence speed index and average time of germination. The experimental design was completely randomized and the means were compared by Tukey's test at 5\% of significance. It was found a significant difference for the percentage of seedling emergence for the vermiculite, humus and sand, with better performance in relation to clay; and for the
\end{abstract}

\footnotetext{
${ }^{1}$ Recebido em 10.03.2012 aceito para publicação em 04.06.2012

${ }^{2}$ Graduação em Ciências Biológicas, Departamento de Botânica, Ecologia e Zoologia- DBEZ/UFRN. E-mail:<kiviaoliv@ yahoo.com.br>. ${ }^{3}$ Programa de Pós-Graduação em Ciências Naturais e Matemática da Universidade Federal do Rio Grande do Norte - UFRN. E-mail: <kallyoliv@yahoo.com.br>.

${ }^{4}$ Universidade Federal do Rio Grande do Norte, Departamento de Botânica, Ecologia e Zoologia - DBEZ/UFRN. E-mail: $<$ magdi-aloufa@bol.com.br>.
} 
emergence speed index and average time of germination, there was no statistically significant difference among the substrates. Concerning the results, we can observe that $\boldsymbol{A}$. colubrina presents a good germinative potential in any of evaluated substrate with the exception of sand, clay. However, for the germination and emergence of angico, it is recommended the use of vermiculite, sand or humus.

Keywords: Caatinga, Germination and Mimosoideae.

\section{INTRODUÇÃO}

Anadenanthera colubrina (Vell.) Brenan, Leguminosae da subfamília Mimosoideae, popularmente conhecida como angico, é uma espécie arbórea com altura entre $12-15 \mathrm{~m}$ e tronco de $30-50 \mathrm{~cm}$ de diâmetro (LORENZI, 2002). De acordo com Marinho (2004), é uma árvore comum em todo o Nordeste, bastante conhecida pelo teor de tanino de sua casca (32\%) e, consequentemente, pela sua indispensável contribuição para a indústria de curtume dos Estados nordestinos. Sua madeira é útil para construção civil, obras hidráulicas, confecção de dormentes, tabuado, podendo ainda ser aproveitada para arborização de parques e praças e para plantio em florestas mistas destinadas à recomposição de áreas degradadas de preservação (LORENZI, 2002).

Segundo Ranieri et al. (2003), a utilização de espécies nativas na reabilitação ambiental não tem sido empregada em virtude da ausência de conhecimento consolidado sobre a biologia, ecologia, técnicas de propagação e manejo dessas espécies. $\mathrm{O}$ angico apresenta reprodução vigorosa, rapidez na germinação, ausência de dormência e alta germinabilidade em ampla faixa de temperatura e plantas com resistência ao dessecamento pela presença do órgão de reserva (MAIA, 2004). Nessa perspectiva, é importante considerar que as características apresentadas pela espécie conferem grande potencial na recuperação de áreas degradadas, concordando com Prestes (2007), ao sugerir que um dos fatores observados na escolha das espécies a serem utilizadas é o seu crescimento rápido, isso porque favorece a rápida cobertura do solo, evitando-se, assim, a perda de nutrientes e materiais sólidos pela erosão.

O tipo de substrato é um aspecto importante para o desenvolvimento de plântulas e deve ser adequado para garantir resultados satisfatórios na produção de mudas. De acordo com Ramos et al. (2002), o substrato tem a finalidade de proporcionar condições adequadas à germinação e ao desenvolvimento do sistema radicular da muda em formação. Além disso, fatores como estrutura, aeração, capacidade de retenção de água e grau de infestação de patógenos podem variar de um substrato para outro, interferindo no processo de germinação e desenvolvimento das mudas (MORAES et al., 2007). Figliolia et al. (1993) colocaram que o substrato tem a função de suprir as sementes de umidade e proporcionar condições adequadas à germinação delas e ao posterior desenvolvimento das plântulas.

Considerando o fato de Anadenanthera colubrina apresentar grande importância econômica e ambiental e tendo em vista, principalmente, o uso intenso e indiscriminado de sua madeira o que põe em risco a existência dessa espécie, este trabalho teve como objetivo avaliar a eficiência de diferentes substratos na germinação de sementes de $A$. colubrina.

\section{MATERIAL E MÉTODOS}

O estudo foi conduzido em casa de vegetação do Laboratório de Biotecnologia de Conservação de Espécies Nativas, do Departamento de Botânica, Ecologia e Zoologia, Centro de Biociências, da Universidade Federal do Rio Grande do Norte, situada a $5^{\circ} 50^{\prime} 31^{\prime \prime}$ de latitude sul e $35^{\circ} 12^{\prime} 7^{\prime \prime}$ de longitude Oeste e altitude média de $50 \mathrm{~m}$, no período de setembro a outubro de 2010 .

As sementes foram obtidas de árvores-matriz no dia 20 de agosto de 2010, no Campus da UFRN e beneficiadas manualmente. O beneficiamento promoveu a abertura dos frutos para obtenção das sementes, com eliminação das malformadas. As sementes selecionadas foram armazenadas em recipiente de vidro e acondicionadas à temperatura ambiente até a realização do experimento. As sementes não passaram por tratamentos pré-germinativos.

A semeadura foi realizada no dia 28 de setembro de 2010 em bandejas de isopor, com 100 células, e colocadas em casa de vegetação coberta com telado

Revista Árvore, Viçosa-MG, v.36, n.6, p.1073-1078, 2012 
(50\% de sombreamento). As sementes permaneceram durante 30 dias em regime de rega diária. Os tratamentos utilizados foram: $\mathrm{T}_{0}$ - vermiculita fina expandida; $\mathrm{T}_{1}-$ húmus; $\mathrm{T}_{2}$ - areia lavada e autoclavada e $\mathrm{T}_{3}$ - areia barrada lavada e autoclavada. A temperatura média diária foi de $26^{\circ} \mathrm{C}$, média das máximas de $30^{\circ} \mathrm{C}$ e médias das mínimas de $24^{\circ} \mathrm{C}$. A média diária de umidade relativa do ar foi de $76 \%$.

A análise estatística dos dados foi feita por delineamento experimental inteiramente casualizado, com quatro tratamentos e quatro repetições de 25 sementes, totalizando 100 sementes por tratamento.

Para avaliação da emergência total de plântulas (EMER) e do índice de velocidade de emergência (IVE), foi feita a contagem diária das plântulas que emergiram até o momento de sua estabilização, iniciando-se as verificações no primeiro dia após a semeadura e encerrando-as no $15^{\circ}$ dia. Os parâmetros avaliados foram: porcentagem de emergência (\%); índice velocidade de emergência (IVE), segundo Maguire (1962); e tempo médio de germinação calculado de acordo com a fórmula proposta por Labouriau (1983).

Os dados obtidos foram submetidos à análise de variância, empregando-se o teste F a 5\%. Para o contraste das médias, utilizou-se o teste de Tukey a $5 \%$ de probabilidade. Os dados em porcentagem de germinação foram transformados em arco-seno x/100 para a obtenção da homogeneidade das variâncias e da normalização de sua distribuição. Na Tabela 1 são apresentadas as médias originais.

Tabela 1 - Valores médios para porcentagem de emergência, índice de velocidade de emergência e tempo médio de germinação de sementes de Anadenanthera colubrina, submetidas a diferentes substratos.

Table 1 - Emergence percentage, Emergence speed index and Average time of germination of Anadenanthera colubrina seed in different substrates

\begin{tabular}{lccc}
\hline Substratos & Emergência (\%) & IVE $\left(\right.$ dias $\left.^{-1}\right)$ & TMG (dias) \\
\hline Vermiculita & $86 \mathrm{a}$ & $6,45 \mathrm{a}$ & $4,87 \mathrm{a}$ \\
Húmus & $78 \mathrm{ab}$ & $6,07 \mathrm{a}$ & $4,43 \mathrm{a}$ \\
Areia & $73 \mathrm{ab}$ & $7,42 \mathrm{a}$ & $3,39 \mathrm{a}$ \\
Areia barrada & $68 \mathrm{~b}$ & $4,58 \mathrm{a}$ & $5,23 \mathrm{a}$ \\
CV $(\%)$ & 13,90 & 26,67 & 29,08 \\
\hline
\end{tabular}

Dados seguidos de mesma letra na coluna não diferem entre si estatisticamente ao nível de $5 \%$ de significância pelo teste Tukey.

\section{RESULTADOS}

A emergência de plântulas iniciou-se no segundo dia após a semeadura (DAS) e foi acompanhada até os 30 dias, no entanto observou-se que ela se estabilizou aos 15 dias, em todos os substratos. Do segundo ao $5^{\circ}$ dia de cultivo foram observados altos índices de emergência. Os resultados da Tabela 1 indicaram valores de emergência estatisticamente iguais para todos os tratamentos, exceto para o substrato $\mathrm{T}_{3}$, que promoveu valor inferior. Observase, nessa tabela, que o $\mathrm{T}_{0}$ registrou o maior valor de plântulas emergidas $(86 \%)$, enquanto o $\mathrm{T}_{3}$ apresentou menor valor $(63 \%)$.

Em relação ao tempo médio de germinação, os resultados apresentados na Tabela 1 indicaram valores estatisticamente iguais para todos os tratamentos, entretanto a areia registrou o menor valor (3,39 dias), diminuindo o tempo médio de germinação das sementes. Os substratos estudados também não influíram nas médias do IVE observadas na Tabela 1. De acordo com os dados, embora não tenha ocorrido diferença significativa entre os demais, a areia $(7,42)$ e a vermiculita $(6,45)$ proporcionaram às sementes índices maiores de velocidade de emergência.

\section{DISCUSSÃO}

Os resultados de porcentagem de emergência deste estudo foram superiores aos obtidos por Melo et al. (2005), que ao estudarem os efeitos de vermiculita, areia e papel germtest na germinação de A. colubrina alcançaram índices inferiores a 70\%, sendo os maiores percentuais observados nos substratos vermiculita e areia. Entretanto, os índices de germinabilidade verificados nesta pesquisa foram inferiores aos encontrados por Serpa et al. (2010), que ao analisarem a influência do substrato e da luminosidade da mesma espécie obtiveram índices entre 86 e 100\%. Eles verificaram os melhores resultados em vermiculita e areia, na ausência de luz e na temperatura de $25^{\circ} \mathrm{C}$, quando comparados com o papel germtest, bem como semelhantes aos observados por Mondo et al. (2008), que, ao realizarem o teste de germinação de sementes com Parapiptadenia rígida (Fabaceae-Mimosoideae) utilizando os substratos vermiculita, papel e rolo de papel, cada um em duas condições de temperaturas, $25^{\circ} \mathrm{C}$ e $30^{\circ} \mathrm{C}$, verificaram índices entre 64 e $96 \%$. Esses autores concluíram que os melhores resultados

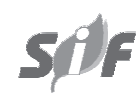

Revista Árvore, Viçosa-MG, v.36, n.6, p.1073-1078, 2012 
encontrados, avaliando a interação temperatura e substrato, foram com a utilização do substrato vermiculita na temperatura de $25^{\circ} \mathrm{C}$.

Já Pacheco et al. (2006), em seus estudos com Myracrodruon urundeuva Fr. All, constataram que a vermiculita e pó de coco foram os substratos que melhor se adequaram à germinação da espécie quando comparados aos substratos papel mata-borrão e areia. Por sua vez, Souza et al. (2007), ao estudarem a germinação de sementes Adenanthera pavonina L. (Leguminosae - Mimosoideae), concluíram que os substratos pó de coco e areia permitiram bom desempenho germinativo, quando comparados com o substrato vermiculita. No entanto, Passos et al. (2007), em seus estudos com sabiá (Mimosa caesalpiniifolia Benth), ao testarem a influência do substrato e utilizando papel-filtro, areia, algodão e vermiculita, observaram que, quanto à taxa de sementes germinadas, os três primeiros não diferiram entre si e apresentaram os melhores resultados. Entretanto, Lima et al. (2006), ao avaliarem o mesmo efeito com sementes de Caesalpinia ferrea (Leguminosae, Caesalpinoideae), não encontraram diferenças significativas entre os substratos papel, areia, vermiculita e plantamax em relação à porcentagem de germinação.

Diante dos substratos analisados, o bom desempenho do substrato vermiculita em relação aos demais pode ser justificado por ele reunir características físicas, como boa retenção de umidade, alta porosidade e baixa densidade, o que muitas vezes proporciona maior facilidade para a plântula emergir (DOUSSEAU et al., 2008). Além disso, segundo Figliolia et al. (1993), a vermiculita é um substrato que vem sendo utilizado com bons resultados para a germinação de sementes de espécies florestais, principalmente devido à sua boa capacidade de absorção e retenção de água.

Quanto ao tempo médio de germinação, neste estudo não foram verificadas diferenças significativas entre os substratos. Os resultados foram diferentes aos encontrados por Lima et al. (2006), ao observarem que em todas as temperaturas o substrato areia apresentou o menor tempo médio de germinação de sementes de Caesalpinia férrea, em comparação com a vermiculita, papel e platamax. Nesse sentido, Rodrigues et al. (2007) afirmaram que, quanto menor o tempo médio, mais vigorosa a amostra.

Em relação ao IVE, os valores sugerem que a espécie emerge rapidamente quando as condições ambientais são favoráveis às sementes, o que evidencia seu vigor. Dessa forma, os tratamentos T0, T1, T2 e T3 proporcionaram a mesma velocidade de estabelecimento das plântulas, independentemente do tipo de substrato. Em trabalho realizado com a mesma espécie, Rodrigues et al. (2007) obtiveram diferenças significativas a $1 \%$ de probabilidade, quando compararam os substratos terra vegetal, areia pura e terra vegetal+areia em diferentes proporções, sendo o solo terra vegetal superior em relação aos demais, no entanto os valores foram inferiores aos índices obtidos neste estudo. Já Serpa et al. (2010), em estudo com a mesma espécie, relataram que a areia, estatisticamente, diferiu da vermiculita, apresentando melhor resultado. No entanto, Aragão (2010), ao estudar diferentes substratos sobre a germinação de sementes de pau-brasil, observou que a areia e a vermiculita promoveram, além da alta taxa de germinação, aumento noíndice de germinação. Aautora complementou a afirmativa dizendo que o sucesso da vermiculita e da areia ocorreu devido ao fato de serem menos densos e mais porosos em relação à argila e à mistura areia e areia barrada.

Nesse aspecto, embora o resultado apresentado pelo substrato areia não tenha diferido estatisticamente dos demais, seu desempenho pode ser justificado como sugeriram Bocchese et al. (2008), pelo fato de a areia favorecer a emergência das plântulas, possivelmente por apresentar menor impedimento físico ao desenvolvimento das raízes. Em relação à vermiculita, concordando com Aragão (2010), o valor do IVE pode ter sido influenciado devido à sua baixa densidade em favorecer a formação estrutural das raízes. Além disso, vermiculita e areia apresentam menor densidade e maior porosidade quando comparados com os substratos areia barrada e húmus.

Ao comparar os valores obtidos entre areia, vermiculita, húmus e areia barrada, todos favoreceram o IVE, no entanto maiores porcentagens de emergência foram registrados nos três primeiros, o que indica uma estrutura de solo que proporciona condições adequadas para emergência. Isso sugere que eles ofereceram boas condições de aeração, absorção e retenção de água ao processo inicial de desenvolvimento das plântulas da espécie em estudo.

Em relação ao húmus de minhoca, apesar de seu desempenho ter sido melhor que o da areia e da areia barrada, pode ser explicado considerando-se que, de acordo com Gonçalves e Poggiani (1996), quando se compara a estrutura física do húmus com a da vermiculita, ambos possuem alta porosidade, porém o primeiro apresenta apenas microporosidade elevada, enquanto

Revista Árvore, Viçosa-MG, v.36, n.6, p.1073-1078, 2012 
a segunda mostra equilíbrio entre a macro e a microporosidade. Dessa forma, essa particularidade do húmus pode induzir a uma diminuição na aeração e, por consequência, influenciar negativamente no desenvolvimento das raízes. Já ao que se refere à areia barrada, seu baixo desempenho pode ser explicado, como sugeriram Lewis e Clementes (1999), devido ao fato de a argila apresentar textura mais fina. Ela retém maiores quantidades de água, assim permitindo menor circulação de ar entre seus poros e, consequentemente, prejudicando a germinação das sementes.

\section{CONCLUSÕES}

Diante das avaliações realizadas, constatou-se que A. colubrina apresenta bom potencial germinativo em qualquer um dos substratos testados, com exceção do substrato areia barrada. Logo, para a germinação e emergência de plântulas de angico, recomenda-se a utilização dos substratos vermiculita, areia ou húmus.

\section{REFERÊNCIAS}

ARAGÃO, A. K. O. A Biotecnologia e a educação ambiental no resguarde a duas espécies em via de extinção na flora da Mata Atlântica brasileira. 132f. Dissertação (Mestrado em Desenvolvimento e Meio Ambiente- PPODEMA) - Universidade Federal do Rio Grande do Norte, Natal, 2010.

BOCCHESE, R. A. et al. Efeitos de diferentes tipos de solo na germinação de sementes de Tabebuia heptaphylla, em casa telada. Revista Cerne, v.14, n.1, p.62-67, 2008.

DOUSSEAU, S. et al. Germinação de sementes de Tanchagem (Plantago tomentosa Lam.): Influência da temperatura, luz e substrato. Ciência e Agrotecnologia, v.32, n.2, p.438-443, 2008.

FIGLIOLIA, M. B.; OLIVEIRA, E. C.; PINÃRODRIGUES, F. C. M. Análise de sementes. In: AGUIAR, I. B.; PINÃ-RODRIGUES, F. C. M.; FIGLIOLIA, M. B. Sementes florestais tropicais. Brasília: ABRATES, 1993. p.137-174.

GONÇALVES, J.L.M.; POGGIANI, F. Substratos para produção de mudas florestais. In: CONGRESSO LATINO-AMERICANO DE CIÊNCIA DO SOLO, 13. Águas de Lindóia, 1996.

Resumos. Piracicaba, Sociedade Latino Americana de Ciência do Solo, 1996. CD-ROM.
LABOURIAU, L.G. A germinação das sementes. Washington: OEA, 1983. 174p.

LEWIS, G. G.; CLEMENTS, R. O. Effect of combined insecticide e fungicide treatments on newly sown swards of Italian and perennial ryegrass using two methods of sowing two rats off seed and $\mathrm{N}$ fertilizer, whit and without herbicide. Grass and Forage Science, v.54, p.155-162, 1999.

LIMA, J. D. et al Efeito da temperatura e do substrato na germinação de sementes de Caesalpinia ferrea Mart. ex Tul. (Leguminosae, Caesalpinoideae). Revista Árvore, v.30, n.4, p.513-518, 2006.

LORENZI, H. Árvores brasileiras: manual de identificação e cultivo de plantas arbóreas do Brasil. 4.ed Nova Odessa: Instituto Plantarum, 2002. p. 188.

MAIA, G. N. Caatinga: árvores e arbustos e suas utilidades. São Paulo: D\&Z, 2004. p.104-114.

MAGUIRE, J. D. Speed of germination-aid in selection and evaluation for seedling emergence and vigor. Crop Science, v.2, n.2, p.176-177, 1962.

MARINHO, I. V. Avaliação do potencial tanífero das cascas do angico vermelho (Anadenanthera colubrina (Vell.) Brenan) e do cajueiro (Anacardium occidentale Linn.) em diferentes reagentes. 2004. 35f. Monografia (Graduação em Engenharia Florestal) - Universidade Federal de Campina Grande, Campina Grande, 2004.

MELO, R. R.; FERREIRA, A. G.; RODOLFO

JUNIOR, F. Efeito de diferentes substratos na germinação de sementes de angico

(Anadenanthera colubrina (Vell.) Brenan) em condições de laboratório. Revista

Cientifica Eletrônica de Engenharia Florestal, v.5, 2005.

MONDO, V. H. V. et al. Teste de germinação de sementes de Parapiptadenia rígida (Benth.) Brenan (Fabaceae). Revista Brasileira de Sementes, v.30, n.2, p.177-183, 2008.

Revista Árvore, Viçosa-MG, v.36, n.6, p.1073-1078, 2012 
MORAES, L. A. C. et al. Indução de brotação apical em mudas provenientes de sementes e do enraizamento de estacas de mangostãozeiro. Acta Scientiarum Agronomy, v.29, n.1, p.665-669, 2007.

PACHECO, M. V. et al. Efeito de temperaturas e substratos na germinação de sementes de Myracrodruon urundeuva Fr. All.

(Anacardiaceae). Revista Árvore, v.30, n.3, p.359-367, 2006.

PASSOS, M. A.; TAVARES, K. M. P.; ALVES, A. R. Germinação de sementes de sabiá (Mimosa caesalpiniifolia Benth.). Revista Brasileira de Ciências Agrárias, v.2, n.1, p.51-56, 2007.

PRESTES, M. T. Efeitos de diferentes doses de esterco de gado, no desenvolvimento e no balanço nutricional de mudas de angico (Anadenanthera macrocarpa). 2007. 62f. Dissertação (Mestrado em Ciências Agrárias) Universidade de Brasília, Brasília, 2007.

RAMOS, J. D., et al. Produção de mudas de plantas frutíferas por semente. Informe Agropecuário, v.23, n.216, p.64-72, 2002.
RANIERI, B. D. et al. Germinação de sementes de Lavoisiera cordata Cogn. E Lavoisiera francavillana Cogn. (Melastomataceae), espécies simpátricas da Serra do Cipó, Brasil. Acta Botânica Brasílica, v.17, n.4, p.523-530, 2003.

RODRIGUES, A. C. C. et al.; Efeito do substrato e luminosidade na germinação de Anadenanthera colubrina (Fabaceae, Mimosideae). Revista Árvore, v.31, n.2, p.187-193, 2007.

SAntanA, D. G.; RAnAl, M. A. Análise de germinação: um enfoque estatístico. Brasília: Universidade de Brasília, 2004. 284 p.

SERPA, P. R. K. et al. Análise germinativa em sementes de Anadenanthera colubrina (VELL.) Brenan Var. colubrina (Vell.) submetidas a diferentes tratamentos. In: JORNADA DE ENSINO, PESQUISA E EXTENSÃO - JEPEX. 10., 2010, Recife. Anais... Recife: UFRPE, 2010.

SOUZA, E. B. et al. Germinação de sementes Adenanthera pavonina L.em função de diferentes substratos e temperaturas. Revista Árvore, v.31, n.3, PAGINAS, 2007. 